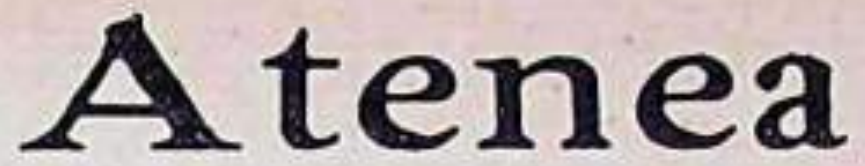

Revista publicada por la Universidad de Concepción

\title{
COMISIÓN DIRECTORA:
}

Enrique Molina, Samuel Zenteno A.. Luis D. Cruz Ocampo. Salvador Gálvez y Abraham Valenzuela C. (Secretario). Eduardo Barrios. Representante General en Santiago

Editor y Agente General: CARLOS JORGE NASCIMENTO

AÑo III MARZO 31 DE 1926 NÚM. 1

Alone

\section{La cátedra imaginaria}

\section{LA MORAL}

A sala iba llenándose lentamente. Nunca se habia visto tanta concurrencia. Algunas señoras entraban envueltas en sus pieles, como en una toga, y tomaban asiento con aire digno y judicial: olras sonreian curiosas, dirigianse preguntas a media voz, examinaban al profesor con sus impertinentes y demostraban la intranquilidad del que espera oir afirmaciones atrevidas, tal vez un tanto escandalosas.

Habia prometido hablarles de Moral.

- Para ustedes-comencé, una vez tranquilizado el auditorio-resulta muy sencillo distinguir el bien del mal.,

Saludos, agradecimientos con la cabeza.

- Les basta leer el Decálogo o interrogar a la conciencia intima que las enseñanzas religiosas les han formado. Saben 
sin reflexionar. Dicen: esto es bueno, esto es malo, y lo elogian - sensuran en ustedes mismas y en las demás. Es una gran ventaja. Pero que el que se halla en el caso de volver a pensar fodas las ideas recibidas tiene delante de si un trabajo abrumador $y$. cuando se pregunía por qué califica unos actos de benéficos, otros de malëficos, otros de indiferentes, necesita remover el subsuelo del mundo para descubrir las raices de la moral.

Por mi parte, después de buscar mucho en el exterior ese -punto de apoyo, que pedía el sabio antiguo, he hallado que los pensamientos describen por el cerebro el mismo círculo que los viajeros alrededor de la Tierra y me he convencido de que. si queremos encontrar algo estable, un punto de partida y de llegada único. debemos quedarnos en nosolros mismos, no salir o no hacernos la ilusión de que hemos salido de nuestro syos.

Ahí reside el secreto de los secretos.

Ahora bien, dentro de ese santuario intimo ¿qué es lo más hondo y lo más simple que descubrimos? ¿El hecho permanente y universal contenido ahi y en todos los séres y todas las cosas? ¿Por qué ley se liga nuestro yo personal a toda la creación?

Para determinar las reglas morales, es decir, las relaciones con nuestros semejantes, me parece indispensable averiguarlo.

Y yo creo que lo sé.

Es, a mi juicio, nada más ni nada menos que el instinlo de conservación del cual derivan lodos los demás instintos.

El instinto de conservación se encuentra en el reino mineral. La piedra del sendero quiere ser piedra y estar ahi. La fuerza de atracción que junta sus moléculas resiste al golpe de la piqueta y la fuerza de su gravedad se opone a la mano empeñada en levantarla. Ambas componen la voluntad de la piedra. cuyo triunfo consistiria en permanecer tal como está y no cambiar de sitio.

Subiendo al reino vegetal, encontramos en la vida de la planta el mismo instinto de conservación con armas de combate 
y manifestaciones de exislencia más variadas. El árbol no sólo quiere ser árbol y estar ahi; para asegurarse, echa raices. crece, busca aire, alimento, agua. trata de extenderse en el espacio y en el tiempo. procura ser muchos árboles para precaverse contra los elementos destructores.

Son nada más que prolongaciones del instinto de conservación. es la voluntad de existir que trepa en la savia. se rodea de corteza, echa ramas, produce hojas, da flores. frutos, semilla.

En el reino animal. estas prolongaciones sulren una transformación prodigiosa. Piedra y árbol. el animal no está inmóvil ni adherido a la tierra. Anda. Sus medios de lucha y también los peligros de su existencia se multiplican. Necesita defender su vida estática y su vida dinámica, busca en mayor espacio los elementos para la subsistencia del individuo y la reproducción de la especie. De ahi infinitas complicaciones, avances y retrocesos, astucias casi humanas, todo un entrecruzamiento de líneas diversas a través de las cuales, como la sangre por las venas, corre y puede siempre distinguirse el impulso del instinto de conservación, la fuga de la muerte y el ansia de ser, de ser cada vez más, de agarrarse con mayor número dé brazos a la existencia.

Resumen de los tres reinos, naturales, mineral, vegetal y animal, el hombre tiene, además, la vida de la inteligencia, tan sutil. impalpable y aparenlemente libre, que se la ha llamado vida inmaterial. vida del espíritu, y se la ha creido, no sin razones, superior a la muerte.

También él está dominado por el mismo principio: el instinto fundamental de conservarse.

Analicemos.

La Ciencia, encaminada a la Verdad, conoce el mundo y descubre sus leyes para poseerlo, para dirigir sus fenómenos y hacerlos servir a la misma causa: la defensa de la vida contra el ataque de las fuerzas exteriores, el viento, el frio, el agua, las fieras. las enfermedades, todos los peligros visibles e invisibles que cercan la existencia.

El Arte, encaminado a la Belleza, constituye un medio de unir los corazones por la misma vibración para salvar el aislamiento 
individual y gozar el mismo goce, sufrir el mismo sufrimiento. dentro de cierto ritmo. Dersigue, fundamentalmente, el placer, un placer alto: $y$ alguien a definido el placer como eun aflujo de fuerza nerviosa, un aumento de vida.

La Moral, por último, encaminada al Bien, es un claro sistema de defensa del hombre, de la familia, de la patria y de la humanidad contra la desorganización y el caos. Todos los preceplos de todos los sistemas nacen de ahi y llevan ahi; y si la moral proviene de algún principio absoluto, a pesar de mi creencia de que no exislen principios absolutos, yo diría que ahi está, que ése es. Examinense los Códigos artículo por artículo y siempre se verá la pena derivarse directa o indirectamente del daño que la culpa causó o pudo causar al instinlo de conservación.

Sólo así se explican y se reducen a la unidad las variaciones de la moral en el espacio y en el tiempo.

En un clima cálido habitado por una raza ardiente, de imaginación exaltada y nervios sensuales, ciertas inclinaciones podrian aniquilar al individuo y disolver el grupo social, si un freno poderoso no las sujetara. El instinto de conservación levanta diques sólidos para contenerlas, atribuye una enorme importancia a faltas que, en climas frios, entre gente apática, carecen de importancia y hasta pueden pasar por ligeras virtudes. En tiempo de guerra, la disciplina, el patriotismo, el valor militar suben al primer plano y obtienen todos los premios; en tiempo de paz se necesitan otras cualidades, la inteligencia sutil, el respeto a la propiedad ajena. la flexibilidad de carácter, y estas son las caracteristicas del buen ciudadano. Asi hay una oscilación continua de valores morales que llega hasta la transmutación. lenta o rápida, de vicios en virtudes y de virtudes en vicios (1).

Variable en el espacio, según los paises. los climas. las razas, y en el tiempo, según las circunstancias del medio am-

(1) Recordaremos una anécdota fipica. Duranie una manilestación palriótica organizada en Valparaíso en época de alarmas internacionales, se corrió por las calles la voz de que habia varios peruanos entre la concurrencia y la multitud empezó a excitarse. Un ladrón le sustrae la cartera a un caballero. La policía coge al muchacho y enderredor suyo se forma un grupo vociferante. Alguien grita: 
biente, la moral varía además según el punto de vista desde el cual se consideren los actos.

El individuo es una agrupación de células organizadas que tienen su instinto de conservación particular. Agrupación de individuos, también lo tienen la familia, y la patria, compuesta de familias, y la humanidad. compuesta de patrias. Lo que sirve a unos suele perjudicar a otros, de donde se derivan la mayoría de los conflictos morales.

Desde el punto de vista del microbio, los remedios son profundamente inmorales. porque lo suprimen y lo matan. Pero desde el punto de vista del individuo son salvadores, porque lo libran de morir victima del microbio. El héroe, al sacrificarse por su pais, comete un suicidio individual; pero la sociedad le eleva estatuas, porque la defiende contra los enemigos que amagarian su existencia. Son diversos instintos de conservación en lucha, cada uno con su moral, sus sistemas, sus premios y sus castigos. (1) El más elevado que conocemos es el instinto de conservación puramente humano: o simbolizado por Cristo, que murió por todos los hombres de todos los paises y de todas las edades. Por eso la colina del Calvario se levanta encima de las más altas montañas y la cruz nó constituye el simbolo. de ninguna nación.

Sin embargo, dirán ustedes, la moral cristiana se basa en

¡Es peruano! La genfe se arremolina, el circulo se estrecha. los gritos condenaforios se repiten. El culpable, pálido, aterrado, ereyendo que van a lyncharlo, exclama:

-Si no soy peruano: isoy pillo, soy pillo!

Para el instinto de conservación patriótico exaltado por la amenaza guerrera del Norte, el enemigo estaba en el Norte y un simple pillo pasaba a la categoria de ente inofensivo, era casi un buen elemento de batalla.

(1) Una revista pidió definiciones del patriotismo y nosotros enviamos ésta. basada en la moral deferminista: Es el instinto de conservación social limitado, abajo, por el insfinto de conservación individual, arriba, por el instinto de conservación humano. Por eso no marchan a la guerra los indiferentes. los egoístas, los fríos de corazón: fienen una patria chica. Ni fampoco los hombres demasiado ardorosos, los grandes humanifarios, los apóstoles, los altruístas: tienen una patria demasiado grande. La irónica ley del círculo también junta aquí los extremos y reune en la misma actifud a los que no aman a sus semejantes y a quienes los aman tanto que, como Cristo, aman aún a sus enemigoss. 
el libre albedrio. opuesto al determinismo orgánico del instinto de conservación.

No discutiré hasta qué punto pueden hallarse en las sentencias del Evangelio argumentos deterministas, aunque estoy cierto de que cualquier exégeta podria descubrir más de alguno. Quiero, solamente, destruir la creencia de que, sin libertad, no existe responsabilidad, la moral desaparece y cesa el derecho de premiar y castigar.

Creo que pensando todo lo contrario nos acercaremos más a la verdad.

Un acto libre ¿qué significa en la existencia de un individuo? Hagamos como los bacteriólogos que aplican el microscopio para investigar y exageremos la libertad del acto hasta dejarlo enorme y puro. Un acto libre es un acto absolutamente desligado de toda causa y de toda consecuencia necesaria; no tiene antepasados ni tendrá descendientes, es un injerto extraño en la cadena de los hechos, algo que el individuo y la sociedad pueden mirar con toda indiferencia. ¿Por qué premiarlo. por qué castigarlo? Nació. se desarrolló, ha muerto. El hombre no tiene nada que ver con él: no es responsable ni del daño que produjo ni del beneficio que pudo traer. La sociedad, si procediera con lógica libre-arbitrísta. se limitaría a conocerlo y nada más. Pero la sociedad no es lógica ni aplica con pureza las teorias del libre-arbitrismo: mezcla siempre, en sus procedimientos, una fuerte dosis de determinismo y por eso califica, premia y castiga, no cree en los hechos aislados y teme siempre y espera la repetición de los hechos delictuosos o benéficos. En esa simple actitud debemos ver la intuición del determinismo. ¿Por qué pensamos que el que ha realizado una buena acción seguirá realizándolas y el que ha cometido una mala continuará cometiéndolas? Porque sabemos que cada cual obe. dece leyes permanentes $y$, aunque no las podemos distinguir y aislar prevemos su oculto mecanismo y nos ponemos en guardia. Yo diria que el mundo ha sido siempre determinista por instinto: porque el hombre de mundo, el hombre de acción. maneja realidades $y$. si no procede de acuerdo con ellas, las 


\section{La cátedrá imaginaria}

realidades no se le someten. ISolamente los sabios, los pensadores y los filósolos abstractos, encumbrados en el reino de la fantasia, poseen el privilegio de inventar y equivocarse por completo!

Observando la historia de las legislaciones penales se verá siempre este fenómeno.

La situación de los jueces libre-arbitristas origina los mâs sutiles e indecifrables conflictos de conciencia. ¿Cómo pensar. medir y contar el grado de libertad. de responsabilidad. de cul. pabilidad? A la complicación de los fenómenos naturales se añade una complicación artificial y de ahí los problemas insolubles. No digo que el determinismo los resuelva y aclare de golpe: afirmaré que da un punto de partida, una base en que apoyarse, algo sólido, concreto, racional. Y profundamente humano. Al concepto de culpa sustituye el de en「ermedad, a la afrenta del castigo, la piedad de la curación, a la venganza de la cárcel sin esperanza, la suavidad paternal del sanatorio. de donde el delincuente puede salir convertido en un hombre bueno.

¿Que la falta de libertad, intensificando el sentimiento de la fatalidad determinista, debilita la responsabilidad personal y constituye una cómoda excusa?

Tampoco.

Cierto facultativo confesaba a una señora debilidades que se ocultan de ordinario entre los hombres, especialmente delante de las damas, y queriendo interpretar para su comodidad la moral determinista, decia:

-No me avergüenzo: todo está en la naturaleza.

La señora le replicó:

-Efectivamente, todo está en la naturaleza. como los olores. desde el más exquisito hasta el más repugnante...

He ahi la base de los valores éticos deterministas, en exacta correlación con los valores estéticos. El mal olor no tiene culpa de ser malo, pero se le aparta: el perfume no tiene mérito en perfumar, pero se le acerca. Tampoco delinquen el leproso, el paralítico, el hombre simplemente feo de cara y, no 
obstante, sufren un verdedero castigo social. ¿Y no llegamos a encontrar injusta las predilecciones otorgadas a la belleza, a la salud, a la simpatía que se recibieron al nacer y no se han conquistado con trabajo?

Desde el punto de vista del instinto de conservación, del deseo de ser, de ser cada vez más, hasta el infinito. la ciencia, el arte y la moral se extienden como caminos paralelos que Irepan la misma colina en cuya cumbre está la perfección, lo desconocido... Dios.

Las señoras guardaban un desconcerlado silencio.

No era, evidentemente. lo que esperaban.

Terminé:

- Por lo demás, todo esto tiene menos importancia de la que parece: porque, en la práctica, las cosas suceden ‘como si

la libertad existiera, y nosotros procedemos ecomo si no existiera.. Mirar bien y nombrar con precisión

-que es lo que he procurado-constituye, en realidad, un simple lujo de la inteligencia. 